\title{
Evolution Characteristics of Pressure-Arch and Elastic Energy during Shallow Horizontal Coal Mining
}

\author{
Yanhai ZHAO, Shuren WANG, Paul HAGAN, Wenbing GUO
}

\begin{abstract}
To ensure safety mining during shallow horizontal coal mining based on the monitoring data of the roof weighting of a typical mining engineering in China, the load distribution characteristics of the roof in the mining field were analysed, and the mechanical model of the pressure-arch in the surrounding rock was established. Then the evolution characteristics of the pressure-arch and elastic energy were revealed during shallow coal mining by theoretical and numerical analyses. Results show that the continuous pressure-arch can form when the horizontal stress exceeds the vertical stress, and the elastic energy of the roof is released by the mining unloading effect. The caved zone of the overlying strata is formed below the inner boundary of the pressure-arch. The elastic energy is accumulated in the pressure-arch and the energy becomes the highest at the front arch foot. The sliding of the caved zone along the shear zone in the mining field can induce the strong roof weighting. The concentrated stress and the released energy during each mining stage increase with the working face advancing, and the height of the shear zone also increases. This study can provide a theoretical reference for similar mining engineering.
\end{abstract}

Keywords: elastic energy; instability; pressure-arch; roof stability; shallow coal mining

\section{INTRODUCTION}

The stability of overlying strata during shallow coal mining, such as the large-scale roof falling and step-like ground subsidence, is the key problem that can restrict the safety mining in the mines [1]. The self-bearing structure of pressure-arch can form in the overlying strata after the coal mining, and this structure can support the load of the upper strata and soil layer, so the weighting intensity of the working face is determined by the caved rock in the unloading zone under the inner boundary of the pressurearch. The elastic energy is accumulated in the pressurearch under the concentrated stress, and the released energy for mining is the internal cause of rock failure [2]. So it is necessary to reveal the distribution characteristics of the stress field and energy field in the mining field, and to analyse the stability of the overlying strata during shallow coal mining based on the evolution characteristics of the pressure-arch.

Currently, most scholars focused on the pressure-arch of the surrounding rock that was mainly the small excavated space such as underground cavern and roadway, and the support was used to stabilize the roof by forming the self-bearing pressure-arch structure [3, 4]. The pressure-arch in the overlying strata during coal mining usually affected the roof stability, and the factors such as buried depth, mining conditions, overburden property, and the horizontal stress also had influences on the distribution of the pressure-arch [5]. With the working face advancing, the inner and outer boundaries of the pressure-arch in the mining field were constantly changed, and the pressure-arch was often located in the area of the concentrated stress. The stress field and energy field in the surrounding rock were redistributed and affected each other, so the stability analysis of the overlying strata was inadequate if neglecting the correlation of these two indexes. The large mining height and long working face were typical characteristics of the shallow coal mining in China. There were differences of the stress distribution and failure characteristics along the strike and dip of the mining field. The abnormal roof weighting control was also a technical problem during the shallow coal mining.

\section{STATE OF THE ART}

The arching effect of the principal stress exists in the underground engineering due to excavation. The pressurearch theory was widely used in the underground tunnel and mining engineering. For example, Poulsen proposed a method for calculating the coal pillar load by pressurearch theory, and the method was verified by the numerical calculation based on the shallow coal mining [6]. Kim et al. investigated the arching effect on a vertical circular shaft by using experimental tests and theoretical analysis, and they quantified the distribution of the lateral earth pressure by three-dimensional arching effect [7].

Xie et al. conducted numerical and physical tests to investigate the stress distribution in the rock surrounding during the fully mechanized top-coal caving. The results showed that a macro-stress shell composed of high stress existed in the surrounding rock, the working face was protected by the stress shell, and the strata of low-stress zone inside the stress shell produced periodic roof weighting. However, the problem of the definition of the stress shell was lack of mechanical criterion [8]. Ren \& Qi studied the stress field during shallow coal mining through field observation and numerical simulation. They pointed out that the bearing structure of the pressure-arch could be formed in the overlying strata, while the pressure-arch was not always stable in the whole mining process, and the mining height and the length of the working face had influences on the pressure-arch. But the instability mechanism and the specific form of the pressure-arch have not been concerned [9]. So the above researches showed that there was a global pressure-arch in the overlying strata in the mining field, but there were differences in the evolution characteristics of the pressure-arch under different mining conditions. For some aspects, such as the forming condition, instability mechanism, and spatial distribution characteristics of the pressure-arch during shallow coal mining are still lacking for a specific research.

He \& Zhang found that a global pressure-arch was formed in the surrounding rock and a loosen zone beneath the pressure-arch was formed in the roof after 
underground engineering excavation. The strata within the loosen zone did not sustain the overburden load and the strata separated from each other [10]. Wang et al. applied pressure-arch theory to predict the collapse scope of a deep-buried tunnel. A curve with a tensile stress of zero was chosen as inner boundary of the pressure-arch. Below the inner boundary of the pressure-arch was the cracked rock in a tension state. The unstable surrounding rock in this scope could cause roof collapse [11]. These researches indicated that because of the instability of the loose strata below the pressure-arch attention should be paid to the failure mechanism of this zone. The elastic energy stored in the primary rock was suddenly released after coal mining. The released energy was transformed into the dissipated energy for the plastic deformation and rock failure process, and the stress in the surrounding rock was partly concentrated after redistribution. So rock failure was the result of the energy release during mining loading and unloading. Huang \& $\mathrm{Li}$ studied the conversion of strain energy in triaxial unloading tests on marble. They found that the initial confining pressure and unloading rate affected the failure mode and strain energy conversion of rock, and the pre-peak conversion rate of strain energy was increased with increase of unloading rate. Failure occurred in the rock specimen with flying fragments after much strain energy was released after post-peak stage [12]. Zhang \& Gao conducted axial loading-unloading experiments to investigate the energy evolution of water-saturated sandstone samples. The results indicated that the saturation process would decrease the pre-peak energy accumulation, while it could increase the dissipated energy but reduce the magnitude and rate of the post-peak energy release [13]. Shabanimashcool \& $\mathrm{Li}$ calculated the potential energy stored in the pressure-arch of the roof beam and the released energy owing to deflection of the beam based on the theory of minimum potential energy, but this research was limited to analysing the stability of the pressure-arch in single roof strata [14]. Rezaei et al. established a mechanical model based on the strain energy balance to determine the mining-induced stress over gates and pillars. They also analysed the height of the distressed zone and the coefficient of stress concentration by using the proposed model, but the relation of the mininginduced stress distribution and strain energy revolution was not established [15].

Since it was not perfect enough about the spatial pressure-arch and elastic energy distribution in shallow coal mining, this study should conduct further work based on the monitoring data of the roof weighting of a typical shallow coal mining. So the typical shallow coal mining in Shendong mining area in China was taken as the engineering background, and the load distribution characteristics of the overlying strata were analysed based on the monitoring data of the support resistance. Through theoretical analysis and numerical simulation, the formation and changing process of the pressure-arch in the overlying strata were studied, and the instability mechanism of the overlying strata during shallow coal mining was revealed by focusing on the accumulation and release law of the elastic energy in the pressure-arch.

The remainder of this study is organized as follows. In Section 3, the comprehensive research methods, such as engineering background, numerical simulation and theoretical analysis are introduced. In Section 4, energy revolution characteristics of pressure-arch during shallow horizontal coal mining are analysed. Finally, conclusions are given in Section 5.

\section{METHODOLOGY}

\subsection{Engineering Background}

The data of roof weighting in Shangwan Mine in Shendong mining area were observed from No. 51101 and No. 51104 panels in No. $1^{-2}$ coal seam. The average thickness of the coal seam of No. 51101 and No. 51104 panels was $6.70 \mathrm{~m}$ at an average depth of $115.40 \mathrm{~m}$, which dipped to $0^{\circ}-3^{\circ}$. The longwall retreating mining method was adopted in each panel, and the full thickness of coal was mined at one time. The full seam top-coalcaving method was used to manage the roof, and the panel widths were $240 \mathrm{~m}$ and $300 \mathrm{~m}$, respectively. The immediate roof was mostly sandy mudstone or siltstone and the main roof was sandstone.

Based on the peak value $P_{\mathrm{m}}$ of the support resistance during the initial weighting and eighteen times periodic weighting, the panel roof weighting characteristics along the strike were obtained as shown in Fig. 1.

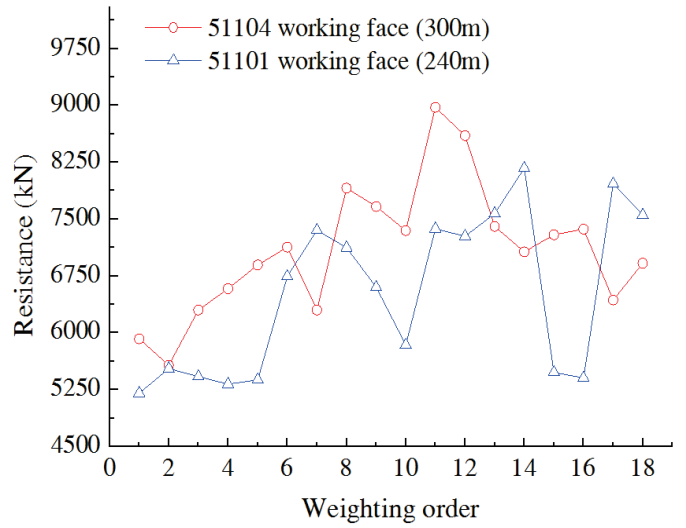

(a) Along strike of the mining field

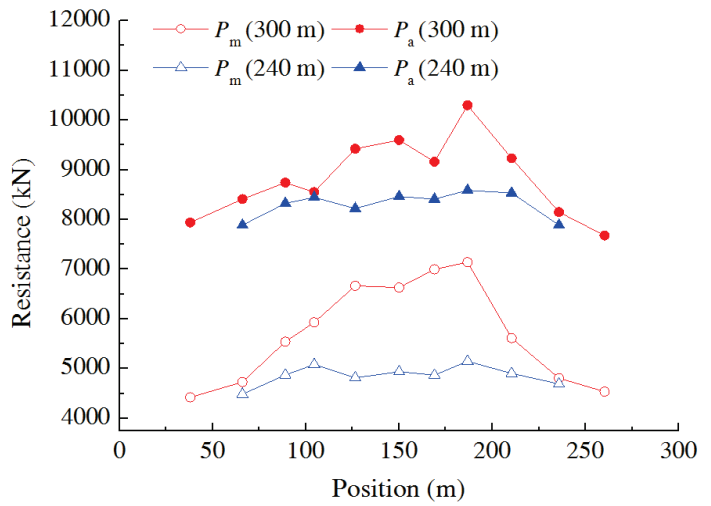

(b) Along dip of the mining field

Figure 1 The panel roof weighting characteristics along the seam strike and dip directions

It can be seen from Fig. 1(a) that the periodic weighting strength increased gradually with the working face advancing, the strong and weak periodicity occurred in the roof weighting. The support resistance wholly increased with increasing of panel width. The strong weighting of the working face with the length of $240 \mathrm{~m}$ 
and $300 \mathrm{~m}$ occurred after the fifth times periodic roof weighting, while the impacted load of the roof existed in the large mining space.

The distribution characteristics of the average value $P_{\mathrm{a}}$ and peak value $P_{\mathrm{m}}$ of the final support resistance along the seam dip direction was shown in Fig. 1(b). The support load and the position of the working face were parabolic, and the support resistance in the middle of the working face was greater than that on both sides, but the load at the head-and tailgate sides was the smallest and distributed as symmetrical arch as a whole. The roof weighting appeared most violently in the middle of the working face and became gentle towards both sides.

The support resistances along the strike and dip of the working face indicated that the size effect affected the load distribution of the overlying strata and the roof weighting, namely the action load of the roof was stronger with the larger mined-out space. The distribution characteristics of the support load in different directions depended on the spatial failure of the overlying strata.

\subsection{Theoretical Analysis}

As shown in Fig. 2, the load of the overlying strata was transferred to the stable surrounding rock in mining field after coal mining.

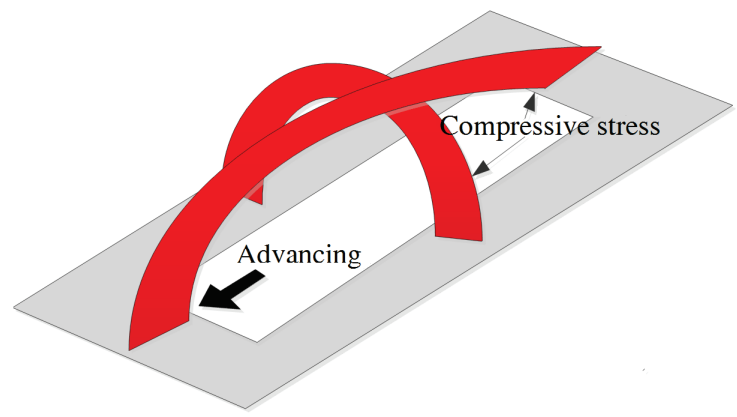

(a) Sketch of spatial distribution of pressure-arch

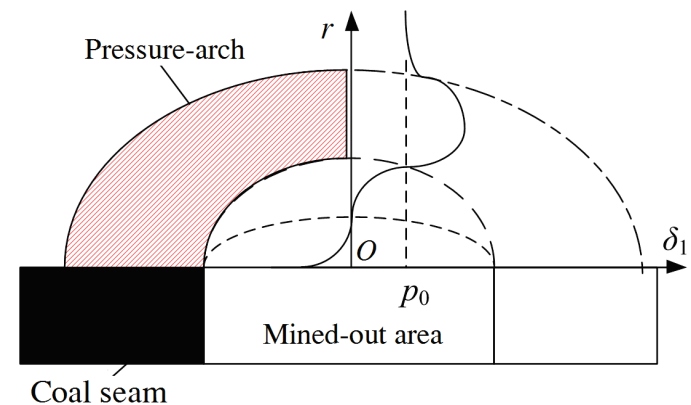

(b) Sketch of major principle stress distribution

Figure 2 The pressure-arch in the overlying strata of mining field

The major principle stress $\sigma_{1}$ was deviated and concentrated in a certain range, while the pressure-arch was the concentrated zone of the compressive stress, and the major principle stress $\sigma_{1}$ in the pressure-arch was greater than the major principle stress $p_{0}$ in the primary rock, then

$$
\sigma_{1}>p_{0}=\gamma h
$$

where $\gamma$ was the average unit weight of the rock strata, $h$ was the buried depth.
The load of the hanging strata above the mined-out area was transferred to the surrounding rock. This transferring action formed the arch top, and the increasing stress contributed to the formation of the arch waist in the surrounding rock. The load of upper strata and loosen soil layer was carried by the rock mass of pressure-arch. The external range of the outer boundary of the pressure-arch was the zone of the primary rock stress, while the zone of the reduced compressive stress and the zone of the tensile stress were located under the inner boundary of the pressure-arch.

The rock mass in deep stratum could be regarded as the elastic medium under the compacted conditions, and a large amount of elastic strain energy was accumulated in the rock under long-term geological action. The energy release during coal mining caused the deformation and failure of the surrounding rock, and the stress was redistributed after the surrounding rock lost its balance state, and the elastic energy was accumulated again in the zone of the concentrated stress.

The sudden energy release was the internal cause of rock failure [16], and the strain energy of rock element in the principal stress space can be expressed as:

$U^{e}=\frac{1}{2 E}\left[\sigma_{1}^{2}+\sigma_{2}^{2}+\sigma_{3}^{2}-2 v\left(\sigma_{1} \sigma_{2}+\sigma_{2} \sigma_{3}+\sigma_{1} \sigma_{3}\right)\right]$

where $\sigma_{1}, \sigma_{2}, \sigma_{3}$ was the principal stress of each direction, $E$ was the elastic modulus, $v$ was the poisson's ratio.

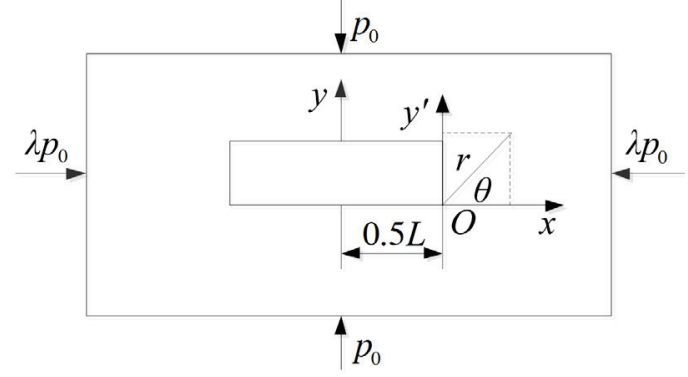

Figure 3 Mechanical model of the surrounding rock

If the stress of the primary rock was in the triaxial anisobaric state, $p_{0}$ was the distant vertical stress, and $\sigma_{1}$, $\sigma_{2}=\sigma_{3}=\lambda p_{0}$ (see Fig. 3), the elastic strain energy $U_{1}^{e}$ of the surrounding rock before excavation was given by

$U_{1}^{e}=\left[\left(1+2 \lambda^{2}\right) p_{0}^{2}-2 v\left(2 \lambda p_{0}^{2}+\lambda^{2} p_{0}^{2}\right)\right] / 2 E$

If the strike length of the working face was $L$, the westergrad stress function being applied [18], considering the plane strain state, the principal stress distribution of the surrounding rock in the mined-out area was given by

$$
\begin{aligned}
\sigma_{1} & =\frac{p_{0}}{2} \sqrt{\frac{L}{r}} \cos \frac{\theta}{2}\left(1+\sin \frac{\theta}{2}\right) \\
\sigma_{2} & =\frac{p_{0}}{2} \sqrt{\frac{L}{r}} \cos \frac{\theta}{2}\left(1-\sin \frac{\theta}{2}\right) \\
\sigma_{3} & =v p_{0} \sqrt{\frac{L}{r}} \cos \frac{\theta}{2}
\end{aligned}
$$


where $L$ was the span along strike direction of the panel, $r$ was the vertical distance from the coal seam top.

Taking the boundary of the mined-out area in the mining field along the horizontal direction as an example, $\theta=0^{\circ}$, the elastic strain energy of the surrounding rock after coal mining was given by

$$
U_{2}^{e}=\left[\left(0.5-0.5 v-v^{2}\right)\right] p_{0}^{2} L / 2 E r
$$

Assuming that the lateral stress coefficient $\lambda=0.5$, the variation of elastic energy $\Delta U^{e}$ of the surrounding rock was given by

$$
\Delta U^{e}=U_{2}^{e}-U_{1}^{e}=\frac{p_{0}^{2}}{2 E}\left[\left(0.5-0.5 v-v^{2}\right) \frac{L}{r}+2.5 v-1.5\right](8)
$$

The pressure-arch of the surrounding rock in the mining field was the increasing zone of the principal stress, and the deformation of the surrounding rock was mainly elastic before this principal stress exceeded its strength, and the elastic energy was accumulated in the pressure-arch. The pressure-arch of the surrounding rock was in the dynamic evolution process during coal mining, and the energy in the strata was also cyclically accumulated and released, so the unloading zone of the strata was the action result of the pressure-arch and the elastic energy. The caved arch of the overlying strata was the cause of roof weighting and disaster, so it was crucial to reveal the instability mechanism of the overlying strata to investigate the evolution characteristics of the pressurearch and elastic energy.

\subsection{Building Computational Model}

As shown in Fig. 4, based on the engineering background of the typical shallow coal mining of Shendong mining area, the numerical model was established by using FLAC ${ }^{3 \mathrm{D}}$ software. The thickness of the coal seam was $7.0 \mathrm{~m}$, the mining height was $6.0 \mathrm{~m}$, the thickness of the siltstone floor was $20.0 \mathrm{~m}$, and that of the roof was $100.0 \mathrm{~m}$. Since focusing on the evolution characteristics of the stress field and energy field of the overlying strata, the difference of rock property between strata was ignored, and the roof strata was unified as the sandstone.

The model size was $400 \mathrm{~m}$ long, $352 \mathrm{~m}$ wide and 137 $\mathrm{m}$ high. The load $1.8 \mathrm{MPa}$ instead of the weight of $12 \mathrm{~m}$ soil layer was applied to the top of the model, while the bottom boundary of the model was fixed and the lateral boundaries of the model were fixed in the horizontal direction.

The position of start mining was $50 \mathrm{~m}$ away from the left boundary, while the advancing distance along the strike was $300 \mathrm{~m}$, and the length of working face along trend was $240 \mathrm{~m}$. The roadway was excavated $50 \mathrm{~m}$ away from both side boundaries along the direction of $X$-axis, while the width of the roadway was $6 \mathrm{~m}$ and the height was $5 \mathrm{~m}$. The physical and mechanical parameters of the model were listed in Tab. 1, and Mohr-Coulomb criteria was used in the numerical calculation.

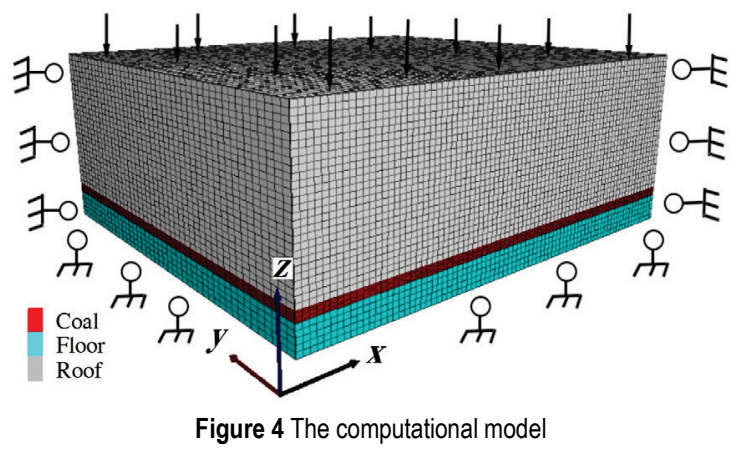

\begin{tabular}{|c|c|c|c|c|c|c|}
\hline Name & 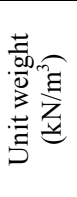 & 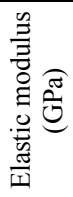 & 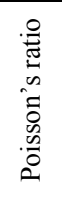 & 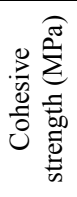 & 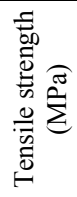 & 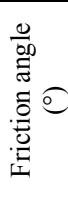 \\
\hline Sandstone & 25.0 & 36.5 & 0.22 & 2.6 & 1.5 & 30 \\
\hline Coal & 13.1 & 12.7 & 0.29 & 1.2 & 0.6 & 27 \\
\hline Siltstone & 24.6 & 37.9 & 0.20 & 4.5 & 3.0 & 40 \\
\hline
\end{tabular}

Table 1 Physical and mechanical parameters of the materials

\section{RESULTS AND DISCUSSION}

As shown in Fig. 5, the major principal stress direction of the overlying strata was deviated after the coal mining, and the vertical stress in the roof decreased while the vertical stress in the lateral surrounding rock increased. The stress in the unloading zone below the deviated principal stress zone decreased, and the major horizontal principal stress was tensile stress in this zone. The principal stress of the overlying strata near the mining field was deviated into an arch, and the zone of increasing principal stress was only formed at two sides of the mined-out area. The continuous circle of the pressure was not formed because of the smaller horizontal stress in the upper strata. The inner boundary of the deviated stress zone moved upward with the working face advancing $50 \mathrm{~m}$, the unloading area expanded and in some of the units occurred tensile failure.

The elastic energy of the unit was monitored using the built-in calculation function and fish language in FLAC $^{3 \mathrm{D}}$, while the lower roof unit $\mathrm{A}$, the middle roof unit $\mathrm{B}$, and the top roof unit $\mathrm{C}$ was regarded as the monitoring object. The changing law of elastic energy of the monitoring unit with the working face advancing $50 \mathrm{~m}$ was shown in Fig. 6. The roof unit $A$ was in the concentrated stress zone before the coal below it was mined, the elastic energy of this unit before the working face advancing $20 \mathrm{~m}$ was in the rising stage, and a large amount of elastic energy was released sharply after the working face advancing $20 \mathrm{~m}$. The unit B was located in the middle position of the roof and the energy in unit B increased gradually after the working face advancing 10 $\mathrm{m}$, but the energy in unit $\mathrm{B}$ increased a little after the working face advancing $20 \mathrm{~m}$ and it was totally released after the working face advancing $30 \mathrm{~m}$. The unit $\mathrm{C}$ was far from the mined area and its energy was kept obviously rising after the working face advancing $10 \mathrm{~m}$.

Overall, the coal mining would lead to energy release in the roof. Some differences existed in the energy evolution characteristics of the strata in different positions under the influence of stress redistribution. The elastic 
energy of the unit was in the rising stage under the action of the concentrated stress, and the unloading zone of the roof strata near the mining area was formed by the sustained elastic energy release.

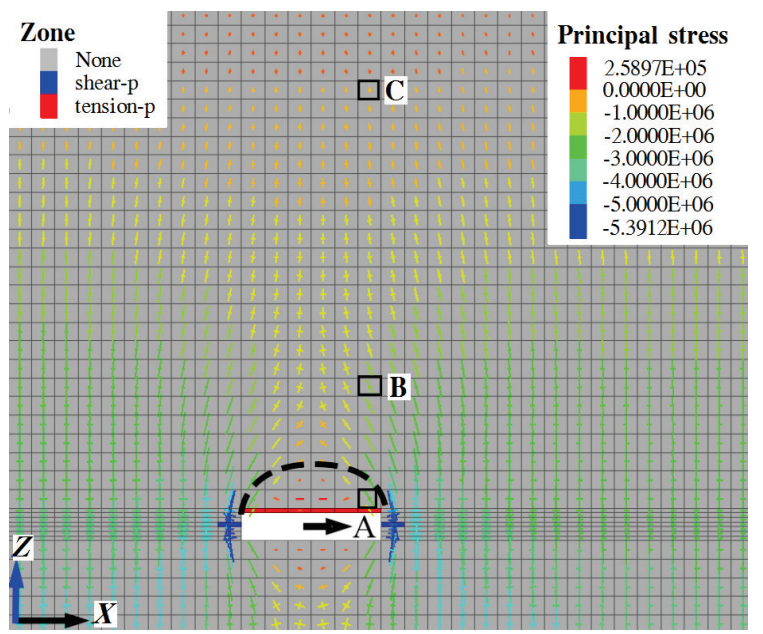

(a) Advancing $30 \mathrm{~m}$

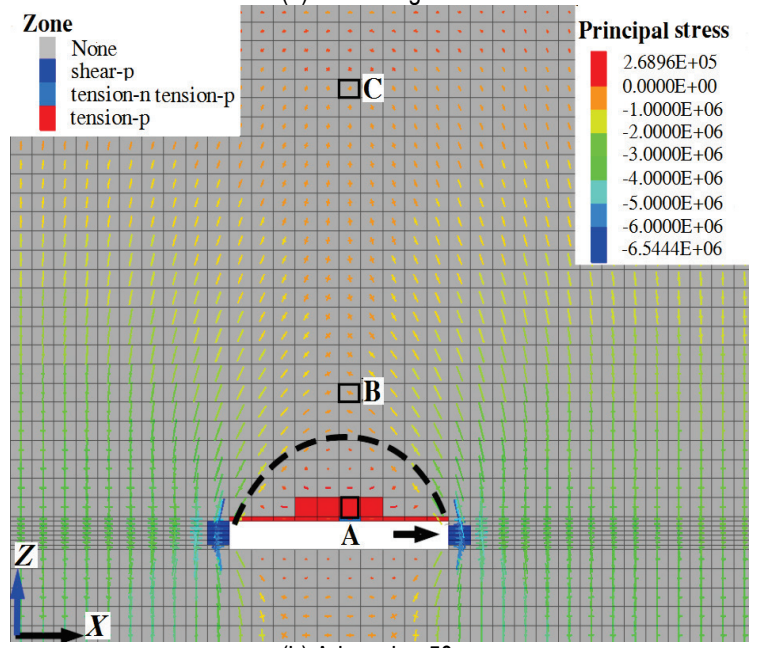

(b) Advancing $50 \mathrm{~m}$

Figure 5 Distribution law of the major principle stress

As shown in Fig. 7, the three-dimensional distribution characteristics of the pressure-arch foot was obtained by extracting the monitoring data of the major principal stress of the roof $2.5 \mathrm{~m}$ away from the coal seam. The stress was reduced in the roof of the mined-out area, and the zone of the concentrated stress was formed in the undisturbed surrounding rock, which was the pressurearch foot of the overlying strata. The exposed area of the overlying strata increased with the working face advancing, and the load carried by the pressure-arch and the peak principle stress of the arch foot increased gradually.

The pressure-arch was the zone of the concentrated stress in the overburden strata, and the elastic energy was accumulated in the pressure-arch. If applying the criterion that the principle stress in the pressure-arch was higher than the stress of the primary rock to judge the arch geometry, the plane shape and spatial distribution characteristics of the pressure-arch could be obtained by programming with the fish language in LAC $^{3 \mathrm{D}}$.

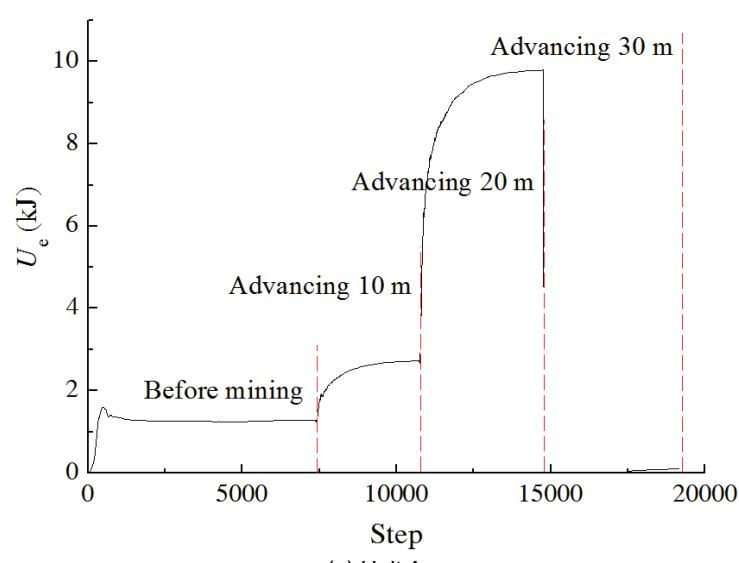

(a) Unit A

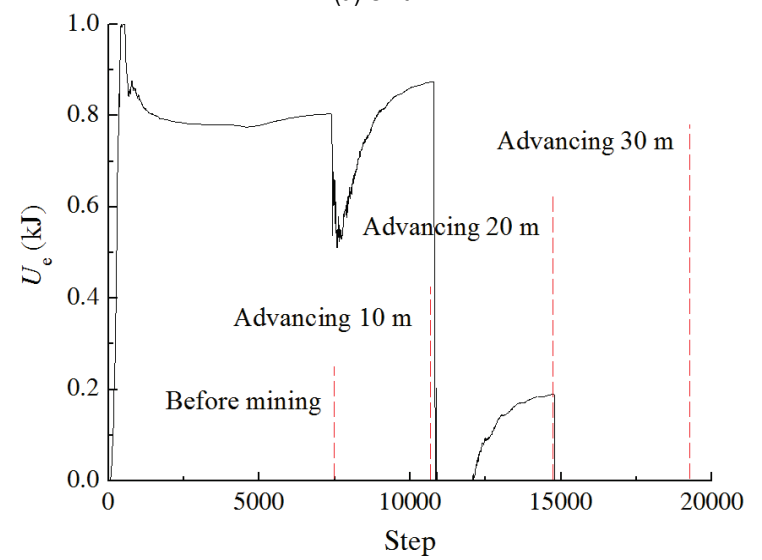

(b) Unit B

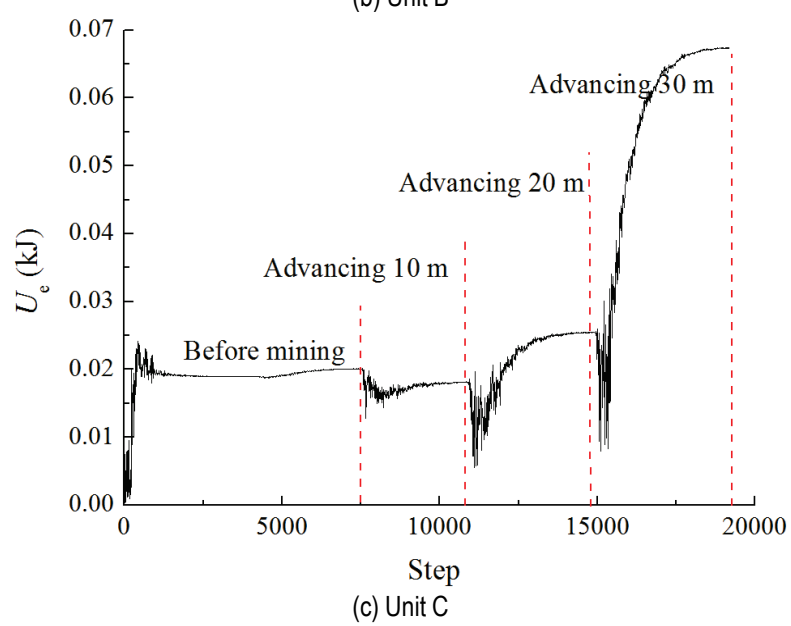

Figure 6 Changing law of elastic energy of the monitoring unit

As the central section view of the working face being shown in Fig. 8, the continuous arching circle of the concentrated principle stress was formed in the surrounding rock with the working face advancing $100 \mathrm{~m}$, and the arch foot moved forward with the working face advancing $150 \mathrm{~m}$ while the inner boundary range of the pressure-arch expanded.

The cutting map of elastic energy in the middle of the working face was shown in Fig. 9. The inner boundary of the pressure-arch was formed after the energy was released when the working face advanced $90 \mathrm{~m}$, and the zone of energy release under the inner part of the arch expanded with the continued mining. The roof strata in the zone of the released energy and the reduced stress were destroyed when the horizontal principle stress reached the tensile strength of the surrounding rock. 


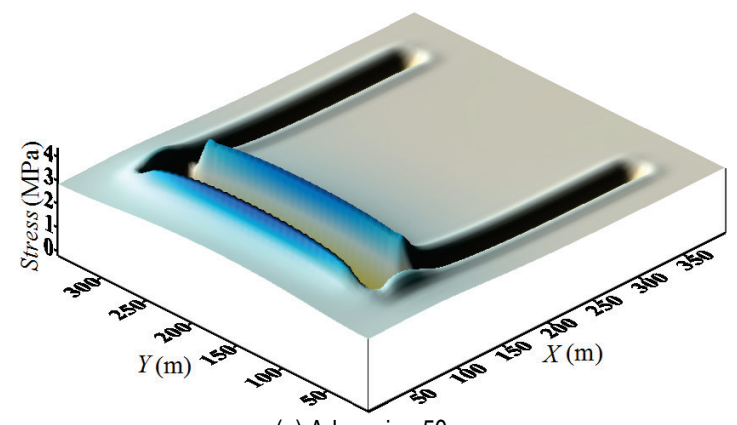

(a) Advancing $50 \mathrm{~m}$

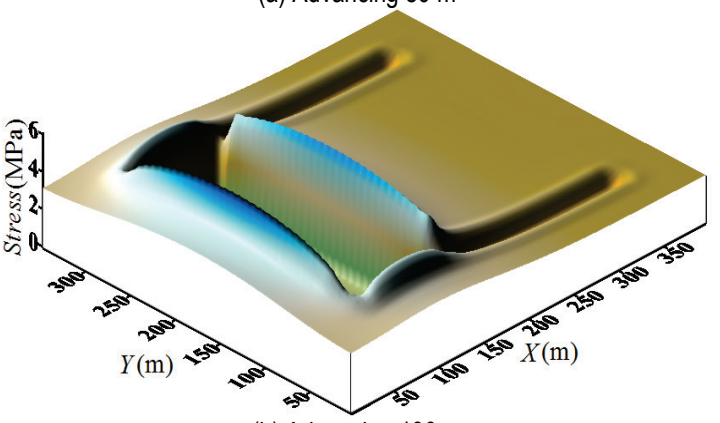

(b) Advancing $100 \mathrm{~m}$

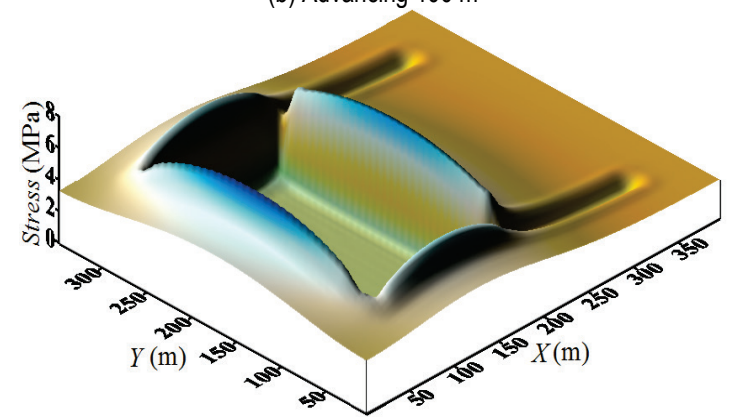

(c) Advancing $150 \mathrm{~m}$

Figure 7 Distribution law of the major principle stress at the pressure-arch foot

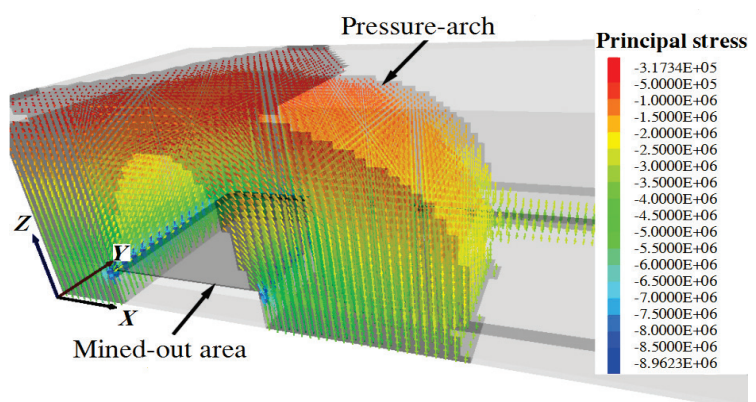

(a) Formation of the three-dimensional pressure-arch

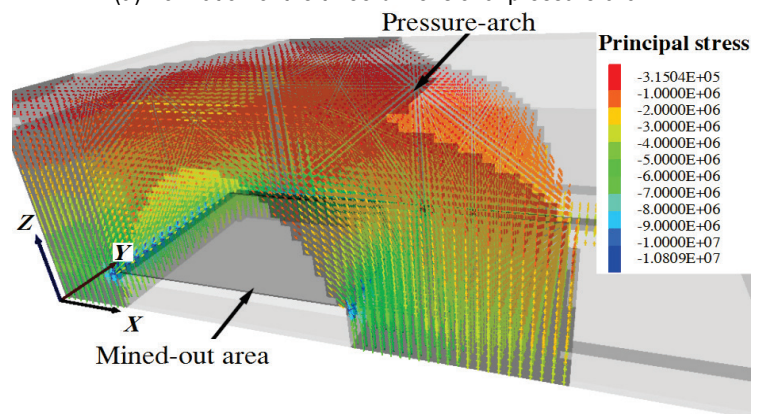

(b) Expansion of the three-dimensional pressure-arch

Figure 8 Cutting view of the three-dimensional pressure-arch

As shown in Fig. 10, the caved arch of the destroyed strata in the unloading zone was formed under the inner boundary of the pressure-arch. The continued coal mining caused the pressure-arch foot move forward, and the inner boundary of the pressure-arch was extended while the caved arch range expanded. The rock mass at two arch feet was under the action of the concentrated stress, the obvious vertical shear zone was formed in the roof strata at the side of the working face, and the caved arch would slide along the fractured zone.

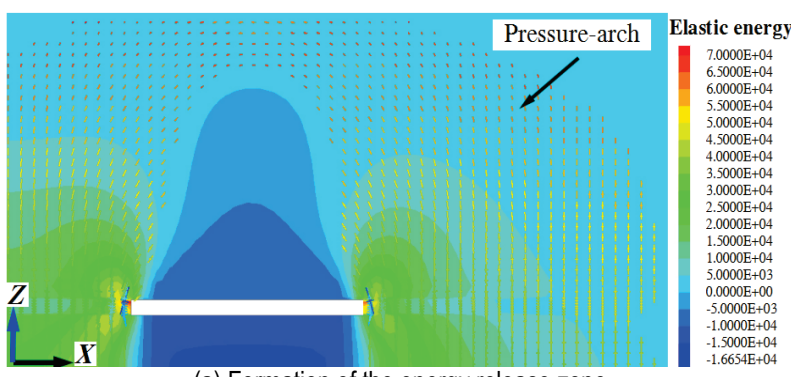

(a) Formation of the energy release zone

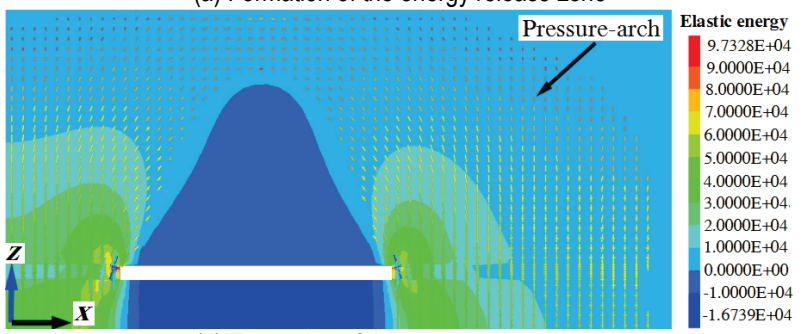

(b) Expansion of the energy release zone

Figure 9 Distribution characteristics of elastic energy in the middle of the working face
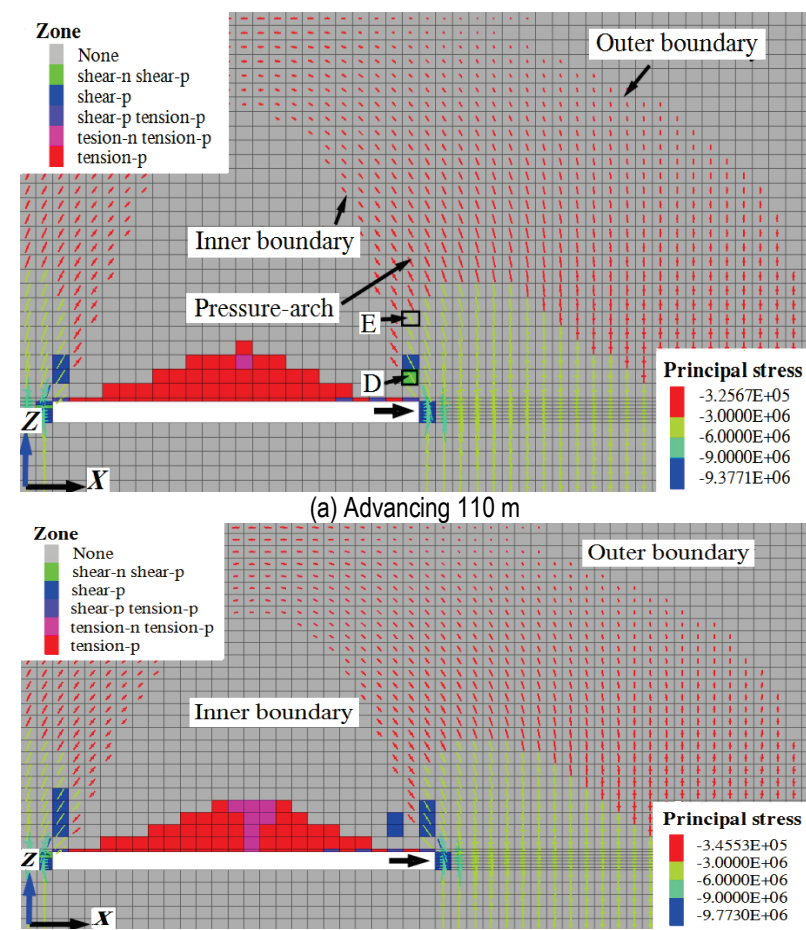

(b) Advancing $120 \mathrm{~m}$

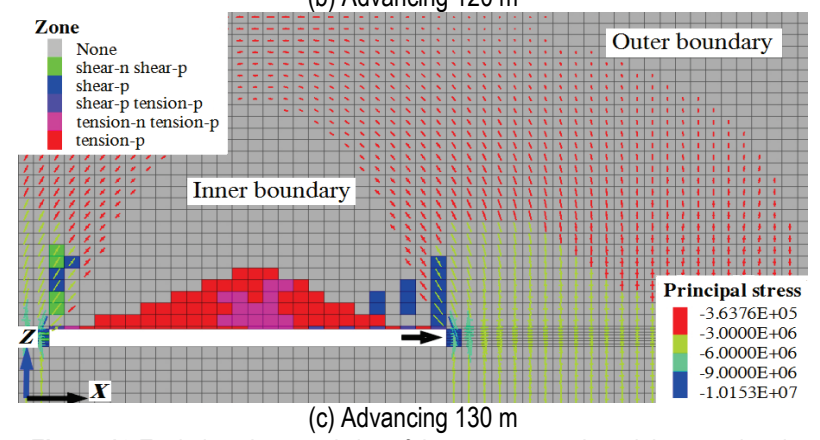

Figure 10 Evolution characteristics of the pressure-arch and the caved arch 
Taking the roof units D and $\mathrm{E}$ which were $5 \mathrm{~m}$ and 25 $\mathrm{m}$ away from the coal seam as the monitoring object, with the working face advancing $110 \mathrm{~m}$, the variation law of the elastic energy of the roof under the action of the pressure-arch could be analysed.

As shown in Fig. 11, when the working face was advanced $110 \mathrm{~m}$, the elastic energy of $29.27 \mathrm{~kJ}$ in the unit $\mathrm{D}$ was released after coal mining, which resulted in the unit being destroyed. The energy was accumulated in the unit again under the concentrated stress in the arch foot, the elastic energy of unit D was fully released for the arch foot moving forward with each mining stage. The peak elastic energy of unit E was relatively small, the released energy was $8.70 \mathrm{~kJ}$ after the coal mining, and the energy was released again for the pressure-arch transferring, but the residual energy still remained in the unit.

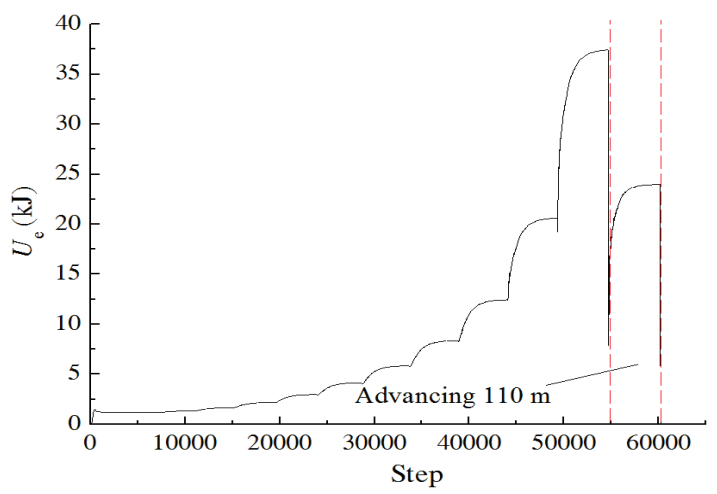

(a) Unit D

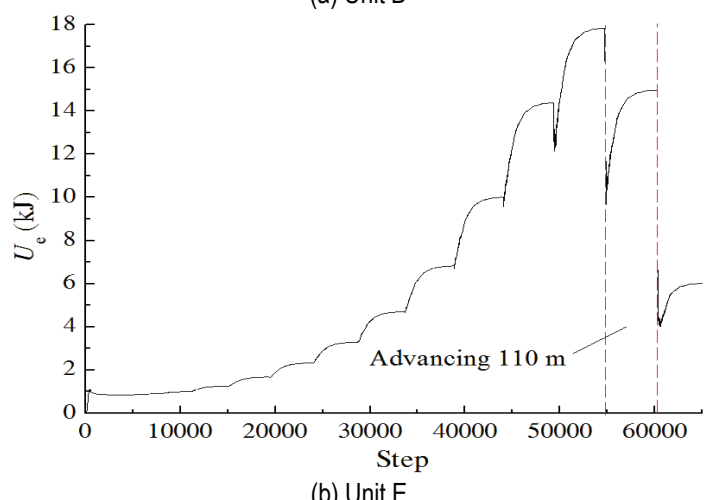

Figure 11 Changing law of the elastic energy of the monitoring units

Compared with the energy monitoring data during the working face advancing $30 \mathrm{~m}$, the energy value was increased totally in the later mining stage, which resulted from the increased load being carried by the pressure-arch and the larger strain of the strata. Under the concentrated stress, the energy in the units in deep position of the surrounding rock was stored with the working face advancing. The concentrated stress was relatively lower near the mining area of the surrounding rock, so the stored energy was lower in this position. Due to the limit of the lower strata, the energy release was inhibited in the upper strata, the units in the middle position of the surrounding rock were not released completely, part of the elastic energy remained in these units.

The distribution characteristics of the principal stress and elastic energy along the trend of the working face after advancing $150 \mathrm{~m}$ were shown in Fig. 12. The global pressure-arch also existed in the strata along trend of the working face, and the zone of released elastic energy was below the inner boundary of the pressure-arch. The caved arch for shear failure was formed in the unloading zone, which caused the distribution of the support resistance in the middle of the working face to be greater than that on both sides.

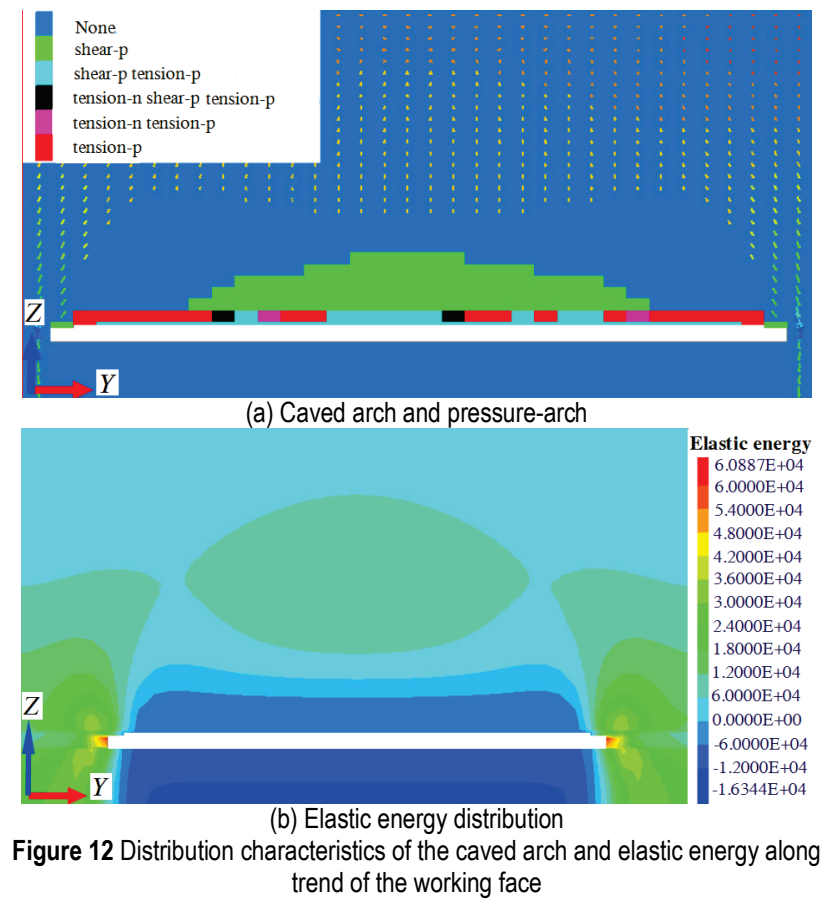

According to the pressure-arch distribution and energy variation, it was known that the elastic energy was mainly stored in the pressure-arch. The energy value in the arch waist and arch feet was relatively higher. The mining action could induce the energy to be released suddenly at the arch foot.

Though the instability of the loosen roof below the pressure-arch could threaten the safety of the working face [4], the global pressure-arch could provide natural protection in the mining field during coal mining. Such factors as the in-situ stress ratio, buried depth, and dip angle could affect the formation and stability of the pressure-arch, and the initial stress condition was a key factor to form the pressure-arch [10, 17]. The stress shell of the surrounding rock under deep fully mechanized topcoal caving conditions could carry and transmit the overburden load, and its internal and external shape changed with the working face advancing. So the loading state and the structural characteristics of the strata in the loosen zone under the stress shell determined the roof weighting characteristics of the working face [8]. The pressure-arch could also be formed in the roof under shallow coal mining condition, while the mining height and the length of the working face had influence on the stability of the pressure-arch.

Due to the initial horizontal stress under shallow coal mining being relatively small, the continuous pressurearch of the overlying strata could not be formed in the initial mining stage, but the global pressure-arch could be formed after the horizontal principal stress exceeded the stress of the primary rock.

The compressive tests and the rating loading and unloading test showed that the sudden release of the elastic energy would induce rock failure [2, 12]. So the 
energy release induced by unloading action of coal mining was the main reason to cause the roof failure in the mining field. Furthermore, the sliding instability of the caved arch of the overlying strata was the main supporting task of the working face during shallow coal mining.

The feet of the pressure-arch were usually the zones of the concentrated stress, which determined the failure characteristics of the roof along the trend and the height of the sliding zone along the strike in the mining field. So the stress concentration and the elastic energy value of the pressure-arch foot were important indexes for predicting the sliding instability of the roof.

\section{CONCLUSION}

To ensure safety mining during shallow horizontal coal mining, taking the typical coal mining in Shendong mining area as the engineering background, the evolution characteristics of the pressure-arch and the elastic energy of the overlying strata were studied, and the distribution characteristics of the pressure-arch in different mining stages were obtained. Furthermore, the failure mechanism of the overlying strata was revealed based on the accumulation and release of the elastic energy. The conclusions are listed as following:

(1) The elastic energy of the roof is released during coal mining, and the continuous pressure-arch is formed when the horizontal principal stress in the mid-span of the roof exceeds the stress of the primary rock. The inner boundary of the pressure-arch may be determined based on the zone of the fully released elastic energy.

(2) The elastic energy is mostly accumulated in the pressure-arch, and the stored energy at the arch foot is the highest. The energy being suddenly released after coal mining can result in rock failure. The concentrated stress and the released energy in the arch foot increase with the working face advancing, and the height of the shear failure zone of the roof also increases.

(3) The unloading zone is located under the inner boundary of the pressure-arch, and the load of the caved arch in this zone is the root of the roof weighting. The pressure-arch feet can determine the failure types of the roof along the trend and the height of the sliding roof zone along the strike of the mining field, the sliding instability of the caved arch in the shear failure zone at the arch feet can cause strong roof weighting.

The strata stability is dependent on the evolution law of the pressure-arch, and enough horizontal stress is the necessary condition for the formation of the continuous pressure-arch during shallow coal mining. So the characteristics of the pressure-arch under different conditions need to be further studied in the future.

\section{ACKNOWLEDGEMENTS}

This study was financially supported by the National Natural Science Foundation of China (51774112; 51474188; 51074140), the International Cooperation Project of Henan Science and Technology Department (182102410060), the Doctoral Fund of Henan Polytechnic University (B2015-67), the Research Fund of State and Local Joint Engineering Laboratory for Gas Drainage \&
Ground Control of Deep Mines (Henan Polytechnic University) (G201614) and Taihang Scholars Program.

\section{REFERENCES}

[1] Ju, J. F. \& Xu, J. L. (2015). Surface stepped subsidence related to top-coal caving longwall mining of extremely thick coal seam under shallow cover. International Journal of Rock Mechanics \& Mining Sciences, 78, 27-35. http://dx.doi.org/10.1016/j.jijmms.2015.05.003

[2] Wang, S. R., Zhao, Y. H., Zou, Z. S., \& Jia, H. H. (2017). Experimental research on energy release characteristics of water-bearing sandstone alongshore wharf. Polish Maritime Research, 24( $\left.\mathrm{S}_{2}\right), 147-153$. https://doi.org/10.1515/pomr-2017-0077

[3] Huang, Z. P., Broch, E., \& Lu. M. (2002). Cavern roof stability-mechanism of arching and stabilization by rockbolting. Tunnelling \& Underground Space Technology, 17(3), 249-261. https://doi.org/10.1016/S0886-7798(02)00010-X

[4] Li, C. C. (2006). Rock support design based on the concept of pressure arch. International Journal of Rock Mechanics \& Mining Sciences, 43(7), 1083-1090. https://doi.org/10.1016/j.ijrmms.2006.02.007

[5] Wang, S. R., Li, N., Li, C. L., \& Cao, C. (2015). Distribution characteristics analysis of pressure-arch in horizontal stratified rocks under coal mining conditions. Tehnicki Vjesnik, 22(4), 997-1004. https://10.17559/TV-20141207160855

[6] Poulsen, B. A. (2010). Coal pillar load calculation by pressure arch theory and near field extraction ratio. International Journal of Rock Mechanics \& Mining Sciences, 47(7), 1158-1165. https://doi.org/10.1016/j.jirmms.2010.06.011

[7] Kim, K. Y., Lee, D. S., Cho, J., Jeong, S. S., \& Li, S. (2013). The effect of arching pressure on a vertical circular shaft. Tunnelling \& Underground Space Technology, 37(6), 10-21. https://doi.org/10.1016/j.tust.2013.03.001

[8] Xie, G. X., Chang, J. C., \& Yang, K. (2009). Investigations into stress shell characteristics of surrounding rock in fully mechanized top-coal caving face. International Journal of Rock Mechanics \& Mining Sciences, 46(1), 172-181. https://doi.org/10.1016/j.jjmms.2008.09.006

[9] Ren, Y. F. \& Qi, Q. X. (2011). Study on characteristic of stress field in surrounding rocks of shallow coalface under long wall mining. Journal of the China Coal Society, 36(10), 1612-1618.

[10] He, L. \& Zhang, Q. B. (2015). Numerical investigation of arching mechanism to underground excavation in jointed rock mass. Tunnelling \& Underground Space Technology, 50, 54-67. https://doi.org/10.1016/j.tust.2015.06.007

[11] Wang, Y. C., Jing, H. W., Zhang, Q., Luo, N., \& Yin, X. (2016). Prediction of collapse scope of deep-buried tunnels using pressure arch theory. Mathematical Problems in Engineering, 3-4, 1-10. https://doi.org/10.1155/2016/2628174

[12] Huang, D. \& Li, Y. R. (2014). Conversion of strain energy in triaxial unloading tests on marble. International Journal of Rock Mechanics \& Mining Sciences, 66(1), 160-168. https://doi.org/10.1016/j.jijmms.2013.12.001

[13] Zhang, Z. Z. \& Gao, F. (2015). Experimental investigation on the energy evolution of dry and water-saturated red sandstones. International Journal of Mining Science and Technology, 25(3), 383-388. https://doi.org/10.3969/j.issn.2095-2686.2015.03.008

[14] Shabanimashcool, M. \& Li, C. C. (2015). Analytical approaches for studying the stability of laminated roof strata. International Journal of Rock Mechanics \& Mining Sciences, 79, 99-108. https://doi.org/10.1016/j.jijmms.2015.06.007 
[15] Rezaei, M., Hossaini, M. F., \& Majdi, A. (2015). Determination of longwall mining-Induced stress using the strain energy method. Rock Mechanics \& Rock Engineering, 48(6), 2421-2433. https://doi.org/10.1007/s00603-014-0704-8

[16] Solecki, R. \& Conant, R. J. (2003). Advanced mechanics of materials, London: Oxford University Press, 147-160.

[17] Abdollahipour, A. \& Rahmannejad, R. (2013) Investigating the effects of lateral stress to vertical stress ratios and caverns shape on the cavern stability and sidewall displacements. Arabian Journal of Geosciences, 6(12), 4811-4819. https://doi.org/10.1007/s12517-012-0698-z

[18] Du, X. L., Wei, J. S., Qian, G., \& Song, H. W. (2015) Influence of geometric features of coal mining area on the rock pressure arch. Chinese Journal of Underground Space and Engineering, 11( $\left.\mathrm{S}_{2}\right), 726-731$.

\section{Contact information:}

Yanhai ZHAO, Postgraduate

School of Civil Engineering, Henan Polytechnic University,

2001 Century Avenue, Jiaozuo, Henan Province, 454003, China

E-mail: qingtingnba@163.com

Shuren WANG, PhD, Professor

(Corresponding author)

1) International Joint Research Laboratory of Henan Province for Underground Space Development and Disaster Prevention, Henan Polytechnic University,

2001 Century Avenue, Jiaozuo, Henan Province, 454003, China

2) School of Mining Engineering, University of New South Wales,

Sydney, NSW 2052, Australia

E-mail: w_sr88@163.com

Paul Hagan, PhD, Associate Professor

School of Mining Engineering, University of New South Wales,

Gate 14 Barke Street, Kensington, Sydney, NSW 2052, Australia

E-mail: p.hagan@unsw.edu.au

Wenbing GUO, PhD, Professor

School of Energy Science and Engineering, Henan Polytechnic University, 2001 Century Avenue, Jiaozuo, Henan Province, 454003, China

E-mail:wbguo@hpu.edu.cn 